\title{
CORRIGENDUM
}

doi:10.1038/nature09031

\section{Asymptomatic deer excrete infectious prions in faeces}

Gültekin Tamgüney, Michael W. Miller, Lisa L. Wolfe, Tracey M. Sirochman, David V. Glidden, Christina Palmer, Azucena Lemus, Stephen J. DeArmond \& Stanley B. Prusiner

\section{Nature 461, 529-532 (2009)}

In this Letter, there was an error in the calculation of infectious doses. The correct sentence should read: Assuming a constant infectious dose of $0 \log \mathrm{ID}_{50}$ units in $3 \mathrm{mg}$ of faeces (equivalent to $2.5 \mathrm{log}$ $\mathrm{ID}_{50}$ units per gram of wet faeces), the cumulative total dose of prions shed during a 10-month period based on $780 \mathrm{~g}$ wet weight of faeces produced per day ${ }^{25}$ is $7.9 \log \mathrm{ID}_{50}$ units, which is similar to 7.8-9.3 log $\mathrm{ID}_{50}$ units found in brains of terminally sick mule deer, assuming an average brain weight of $200 \mathrm{~g}$. Because the estimated values in faeces and deer brain are both $\sim 1,000$-fold lower than originally published, this error does not affect the overall conclusions of the paper.

It is noteworthy that mule deer brain samples were bioassayed in $\operatorname{Tg}($ ElkPrP) mice by inoculation of $30 \mu \mathrm{l}$ of a $1 \%(\mathrm{w} / \mathrm{v})$ homogenate, and faecal samples by inoculation of $30 \mu \mathrm{l}$ of a 14\% (w/v) homogenate. The resulting $\mathrm{ID}_{50}$ units in brain and faecal homogenates were normalized to reflect the $\mathrm{ID}_{50}$ units in $30 \mu \mathrm{l}$ of $10 \%$ brain and $10 \%$ faecal homogenates to facilitate comparisons (see Supplementary Information associated with original manuscript).

25. Arthur, W. J. \& Alldredge, A. W. Seasonal estimates of masses of mule deer fecal pellets and pellet groups. J. Wildl. Mgmt 44, 750-752 (1980). 